\title{
Suspected acute exacerbation of idiopathic pulmonary fibrosis associated with interferon alpha therapy for hepatitis C: case report
}

\author{
Victoria Yee-May Ling ${ }^{1 *}$, Marianne Mortimore ${ }^{2}$ and David J Serisier ${ }^{1,3,4}$
}

\begin{abstract}
Interferon alpha (IFNa) has immune stimulatory actions implicated in its pulmonary toxicities. We describe deterioration of idiopathic pulmonary fibrosis (IPF) associated with IFNa treatment for chronic hepatitis C in a 58 year old woman culminating in a fatal suspected acute exacerbation of IPF (AE-IPF). Caution should be exercised in the use of IFNa in subjects with concomitant IPF given its known immunostimulatory effects and possible role in this suspected AE-IPF.
\end{abstract}

Keywords: Idiopathic pulmonary fibrosis / usual interstitial pneumonia, Acute exacerbation of idiopathic pulmonary fibrosis, Interferon alpha, Hepatitis C

\section{Background}

Pulmonary toxicity is a recognised complication of interferon alpha (IFN $\alpha$ ), thought to be related to its immunostimulatory effects. IFN $\alpha$ has been shown to influence the immune system along multiple pathways including augmentation of proinflammatory and profibrotic cytokines (Midturi et al. 2004). Interstitial pneumonitis is the most commonly documented pulmonary toxicity of IFN $\alpha$ (Midturi et al. 2004), but potential deterioration of existing interstitial lung disease needs to be highlighted. We describe a case of progression of usual interstitial pneumonia (UIP)/idiopathic pulmonary fibrosis (IPF) during IFN $\alpha$ treatment, which culminated in a fatal acute exacerbation of IPF (AE-IPF).

\section{Case description}

A 58 year old woman with probable UIP/IPF and hepatitis $\mathrm{C}$ virus $(\mathrm{HCV})$-related Child-Pugh A liver cirrhosis developed an oesophageal variceal bleed. Hepatitis C was associated with moderate inflammatory activity (Metavir score A3F4), previous hepatic decompensation with ascites and F3 oesophageal varices treated with prophylactic ligation. She had a history of tobacco-

\footnotetext{
* Correspondence: viki_ling@hotmail.com

${ }^{1}$ Department of Respiratory Medicine, Mater Adult Hospital, South Brisbane, Qld 4101, Australia

Full list of author information is available at the end of the article
}

related chronic obstructive pulmonary disease (COPD). Eighteen months before admission, high-resolution computed tomography (HRCT) of the chest demonstrated lower zone predominant subpleural interstitial fibrosis with honeycombing consistent with UIP/IPF (see Figure 1a), in addition to centrilobular emphysema.

Five months before admission, she commenced pegylated-interferon alpha- $2 \alpha$ and ribavirin. Lung function tests repeated after 1 month of therapy showed 6\% reduction in forced vital capacity (FVC) (see Table 1), unassociated with ascites at that time. Pulmonary HRCT after 2 months of therapy showed deterioration of fibrotic changes (see Figure 1b).

On admission, she received intravenous octreotide, prophylactic ceftriaxone and endoscopic variceal banding. On day 3 , she developed progressive hypoxaemia, requiring high flow nasal prong oxygen to achieve oxyhaemoglobin saturations of $96 \%$. She was febrile to $38.3^{\circ} \mathrm{C}$. HRCT of the chest demonstrated diffuse ground-glass change superimposed on markedly deteriorated bilateral pulmonary fibrosis with honeycomb changes (see Figure 2). Intravenous piperacillin/tazobactam, vancomycin, tobramycin and azithromycin were commenced. Sputum specimens cultured Pseudomonas aeruginosa and non-multiresistant methicillin-resistant Staphylococcus aureus (nmMRSA). On day 6, intravenous hydrocortisone was commenced. On Day 7, bronchoalveolar lavage was performed and 

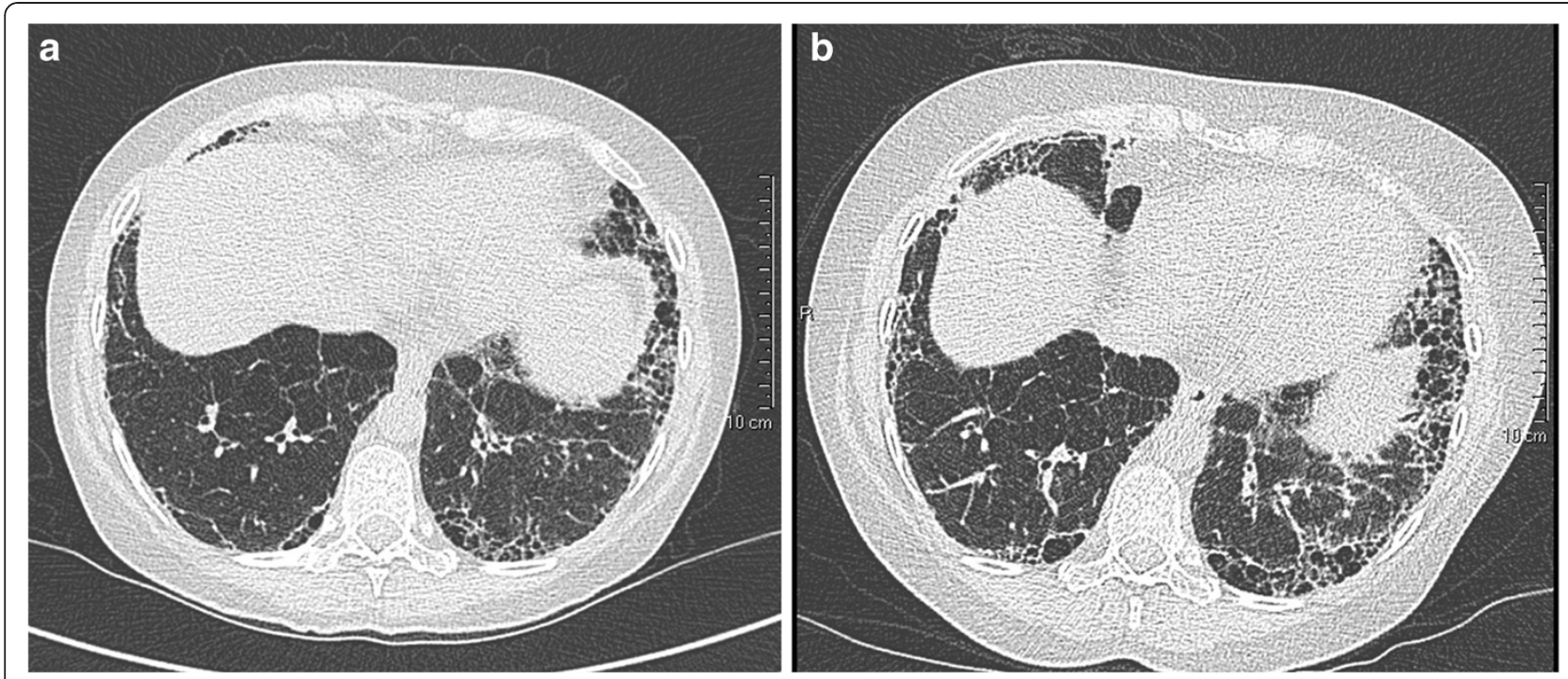

Figure 1 Serial chest HRCT images in relation to IFNa therapy. Progression of subpleural interstitial fibrosis and honeycombing from (a) 9 months prior to the current presentation, prior to commencement of IFNa to (b) 3 months prior, 2 months after commencing IFNa therapy.

specimens again grew nmMRSA, however tested negative for all other pathogens including Pneumocystis jiroveci (carinii). Transthoracic echocardiogram demonstrated normal left ventricular function. On day 10 , there was further deterioration in oxygenation and she required high flow oxygen via mask to achieve oxygen saturations of 90\%. Pulse intravenous methylprednisolone was commenced however her respiratory status continued to deteriorate. Escalation of therapy including endotracheal intubation was thought to be futile and she died on day 14 .

\section{Discussion and evaluation}

The immunostimulatory properties of IFNa and its recognised risks of pulmonary toxicity including pneumonitis create a strong case for implicating IFN $\alpha$ in potentiating the current deterioration of IPF with a possible contribution to the subsequent suspected AE-IPF. This patient demonstrated objective progression of her probable UIP soon after commencing IFN $\alpha$, with both

Table 1 Respiratory function tests of the patient with times in reference to her admission

\begin{tabular}{lcc}
\hline & 9 months earlier & 4 months earlier \\
\hline FEV1 - L (\% predicted) & $2.26(88)$ & $2.13(83)$ \\
FVC - L (\% predicted) & $3.60(111)$ & $3.38(105)$ \\
FEV1/FVC (\% predicted) & $0.63(79)$ & $0.63(80)$ \\
TLC - L (\% predicted) & $5.38(106)$ & $5.05(100)$ \\
DLCO $N A-\mathrm{mL} / \mathrm{min} / \mathrm{mmHg} / \mathrm{L}$ & $1.62(35)$ & $1.64(35)$ \\
(\% predicted) & &
\end{tabular}

FEV1, forced expiratory volume in one second; $F V C$, forced vital capacity; $T L C$, total lung capacity; DLCO, carbon monoxide diffusing capacity; VA, alveolar volume. physiologic (within 1 month) and radiologic (within 2 months) evidence of deterioration. The $6 \%$ decline in FVC was felt to be within the limits of variability, although recent data have shown that FVC decline of $>5 \%$ predicts a doubling of one year mortality (Zappala et al. 2010).

The acute respiratory decline during the described admission was suspected to be secondary to AE-IPF. Although $P$. aeruginosa and nmMRSA were isolated from respiratory specimens at the time, the patient received appropriate antibiotic therapy promptly at onset (prior to culture of the organisms) and subsequent bronchoscopy (performed because of progressive hypoxia) did not reculture Pseudomonas. Furthermore, her clinical course was marked by relentlessly progressive, antibiotic-unresponsive, hypoxic respiratory failure without evidence of sepsis, features much more consistent with AE-IPF than nmMRSA pneumonia. While exclusion of infection forms part of Collard's proposed criteria for definition of AE-IPF (Collard et al. 2007), infectious agents have been found in up to one-third of subjects with this diagnosis (Borchers et al. 2011) and others have argued that diffuse alveolar damage superimposed upon IPF represents a common endpoint that may be the result of a range of potential triggers, including infection (Corte and Wells 2010).

\section{Conclusions}

Given that IFN $\alpha$ is now part of standard therapy for chronic HCV infection and the rising incidence of UIP/ IPF in Western countries (Navaratnam et al. 2011), it is likely that subjects with UIP/IPF will be increasingly exposed to this therapy. The possibility that IFN $\alpha$ may result in significant, potentially fatal deterioration in 

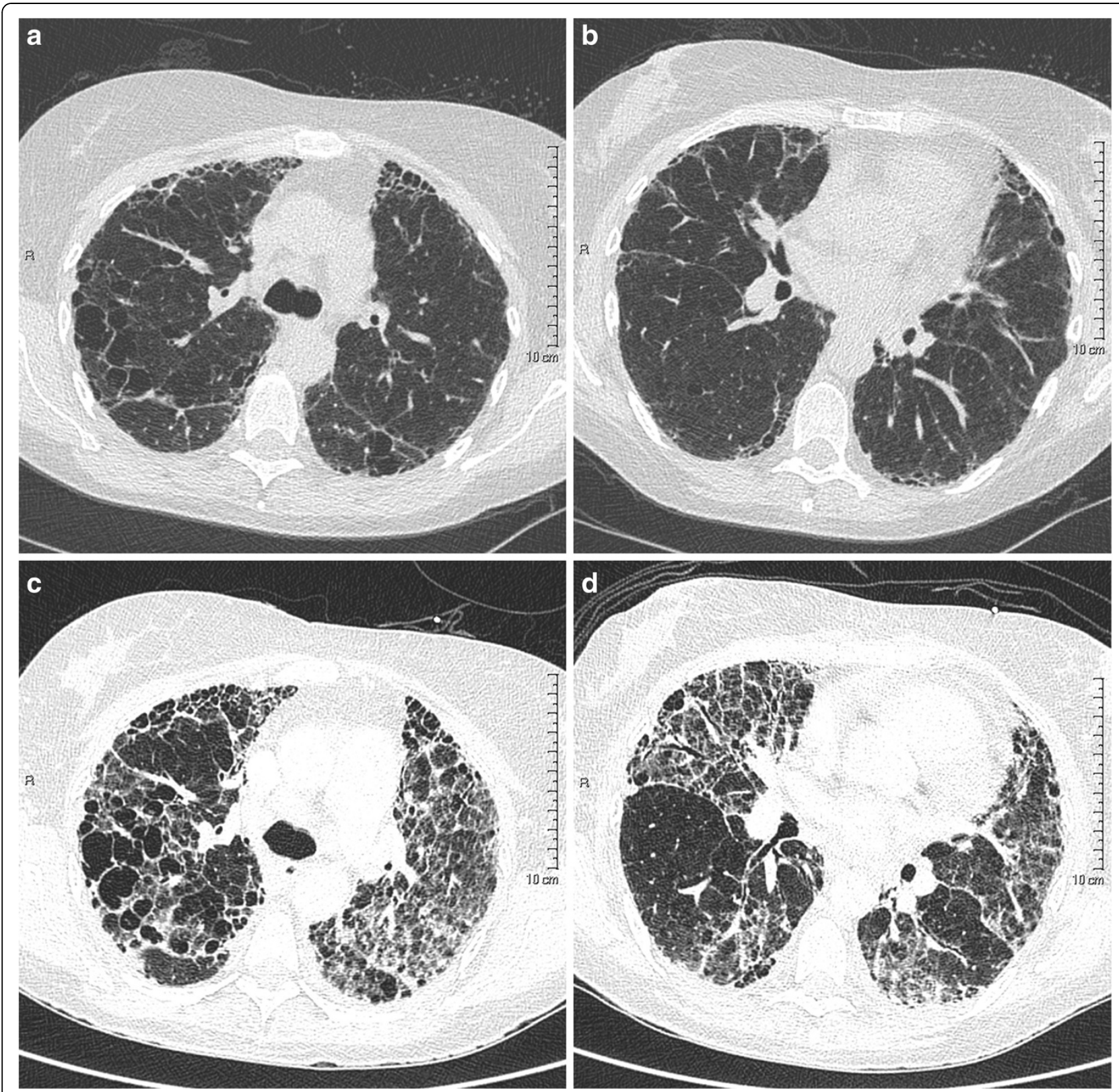

Figure 2 Serial chest HRCT images in relation to the suspected AE-IPF. HRCT performed during the exacerbation (c) and (d) demonstrates diffuse ground glass opacity with marked progression of the underlying fibrosis and honeycombing compared with 3 months prior (a) and (b).

underlying UIP/IPF necessitates careful consideration prior to embarking upon this therapy in these subjects. Whilst the current case in no way demonstrates causality, we would advise close monitoring and a low threshold for cessation of this therapy in the event of deterioration.

\section{Abbreviations}

AE-IPF: Acute exacerbation of idiopathic pulmonary fibrosis; COPD: Chronic obstructive pulmonary disease; DLCO: Carbon monoxide diffusing capacity: FEV1: Forced expiratory volume in one (1) second; FVC: Forced vital capacity; HCV: Hepatitis C virus; HRCT: High resolution computed tomography: IFNa: Interferon alpha; IPF: Idiopathic pulmonary fibrosis; nmMRSA: Nonmultiresistant methicillin resistant staphylococcus aureus; TLC: Total lung capacity; UIP: Usual interstitial pneumonia; VA: Alveolar volume.

\section{Competing interest}

The authors declare that they have no competing interests.

\section{Authors' contributions}

VYML drafted and revised the manuscript. MM helped to draft and revise the manuscript. DJS was involved in the design, drafting and revising of the manuscript. All authors read and approved the final manuscript.

\section{Author details}

'Department of Respiratory Medicine, Mater Adult Hospital, South Brisbane, Qld 4101, Australia. ${ }^{2}$ Department of Gastroenterology, Mater Adult Hospital, South Brisbane, Qld, Australia. ${ }^{3}$ University of Queensland, Mater Health Services, South Brisbane, Qld, Australia. ${ }^{4}$ Immunity, Infection and Inflammation Program, Mater Medical Research Institute, Mater Health Services, South Brisbane, Qld, Australia. 
Received: 29 October 2012 Accepted: 22 February 2013

Published: 12 March 2013

\section{References}

Borchers AT, Chang C, Keen CL, Gershwin ME (2011) Idiopathic pulmonary fibrosis_an epidemiological and pathological review. Clin Rev Allergy Immunol 40:117-134

Collard HR, Moore BB, Flaherty KR, Brown KK, Kaner RJ, King TE Jr, Lasky JA, Loyd JE, Noth I, Olman MA, Raghu G, Roman J, Ryu JH, Zisman DA, Hunninghake GW, Colby TV, Egan JJ, Hansell DM, Johkoh T, Kaminski N, Kim DS, Kondoh Y, Lynch DA, Müller-Quernheim J, Myers JL, Nicholson AG, Selman M, Toews GB, Wells AU, Martinez FJ (2007) Acute exacerbations of idiopathic pulmonary fibrosis. Am J Respir Crit Care Med 176:636-643

Corte TJ, Wells AU (2010) Diffuse alveolar damage in idiopathic pulmonary fibrosis: does aetiology matter? Respirology 15:873-875

Midturi J, Sierra-Hoffman M, Hurley D, Winn R, Beissner R, Carpenter J (2004) Spectrum of pulmonary toxicity associated with the use of interferon therapy for hepatitis C: case report and review of the literature. Clin Infect Dis 39:1724-1729

Navaratnam V, Fleming KM, West J, Smith CJ, Jenkins RG, Fogarty A, Hubbard RB (2011) The rising incidence of idiopathic pulmonary fibrosis in the U.K. Thorax 66:462-467

Zappala CJ, Latsi PI, Nicholson AG, Colby TV, Cramer D, Renzoni EA, Hansell DM, du Bois RM, Wells AU (2010) Marginal decline in forced vital capacity is associated with a poor outcome in idiopathic pulmonary fibrosis. Eur Resp J 35:830-835

doi:10.1186/2193-1801-2-101

Cite this article as: Ling et al.: Suspected acute exacerbation of idiopathic pulmonary fibrosis associated with interferon alpha therapy for hepatitis C: case report. SpringerPlus 2013 2:101.

\section{Submit your manuscript to a SpringerOpen ${ }^{\circ}$ journal and benefit from:}

- Convenient online submission

- Rigorous peer review

- Immediate publication on acceptance

- Open access: articles freely available online

- High visibility within the field

- Retaining the copyright to your article

Submit your next manuscript at $\boldsymbol{\wedge}$ springeropen.com 